\title{
TO INVESTIGATE THE IMPACT OF FAMILY-CENTERED EDUCATION ON THE QUALITY OF LIFE OF PATIENT WITH STOMA
}

\author{
Fariba Nasiri Ziba1', Shadie Kanani²
}

${ }_{1}^{1}$ Faculty Member, MSc, Department of Medical Surgical Nursing, ET/WOCN, IIWCC, School of Nursing and Midwifery, Iran University of Medical Sciences, Tehran, Iran.

2MSc. Student of Nursing, Department of Medical Surgical Nursing, School of Nursing and Midwifery, Iran University of Medical Sciences, Tehran, Iran.

\begin{abstract}
BACKGROUND
ABSTRACT

As the third and second leading cause of cancer deaths, both all around the world and in developing countries colon-rectal cancer is developing rapidly. In treatment methods accompanied with placing digestive stoma, family care is regarded as an important support in the process of this chronic illness, which positively affects the general health system.

The research aim was to investigate the impact of family-centered education on quality of life in patients with gastric stoma (colostomy and ileostomy).
\end{abstract}

\section{MATERIALS AND METHODS}

This research is a non-randomised clinical trial research performed on 61 subjects with gastrointestinal stomatitis and their companion (members of the family in care process) who had criteria for entering the research. At first the experimental group (30 people) and control group (31 people) completed the standard quality of life questionnaire (OSH-COH-QOL). To conduct the training, the test group received a family-centered approach training in three sessions. During the intervention period, the control group received care and general education. Two months later, the quality of life of patient with gastric stoma was re-evaluated. Then, data was analysed by SPSS software 22 with Chi-square, t-test and independent t-test.

\section{RESULTS}

Based on the findings, there was no significant difference between the two groups of family-centered and control groups in terms of demographic characteristics. The independent t-test results showed in the post-intervention stage the quality of life score and physical health dimensions compared to the control group were statistically significant.

\section{CONCLUSION}

The results showed with family-centered education approach can improve the quality of life of patient with gastric stoma.

\section{KEY WORDS}

Gastrointestinal Stomata, Quality of Life, Family-Centered Approach, Education.

HOW TO CITE THIS ARTICLE: Ziba FN, Kanani S. To investigate the impact of family-centered education on the quality of life of patient with stoma. J. Evolution Med. Dent. Sci. 2018;7(41):4415-4419, DOI: 10.14260/jemds/2018/986

\section{BACKGROUND}

Colon and rectum cancer is both the second and third leading cause of death from cancer in developing countries and all around the world (Hoentjen et al, 2012). Treatments for colorectal cancer include surgery, radiotherapy and chemotherapy related with placing digestive stoma. The stoma is the result of an outflow from the small intestine (ileostomy) or colon (colostomy) of the intestine and the period may be temporary to protect the low anastomosis in rectum or permanent cancer usually for upper rectal cancer, or due to the other reasons such as weak control of spinal anaesthesia (Fucini et al, 2011). The stoma causes some disorders including colon cancer, diverticulitis, inflammatory bowel disease, trauma, congenital anomalies and other

'Financial or Other Competing Interest': None.

Submission 28-08-2018, Peer Review 20-09-2018,

Acceptance 27-09-2018, Published 08-10-2018.

Corresponding Author:

Shadie Kanani,

MSc. Student of Nursing,

Department of Medical Surgical Nursing,

School of Nursing and Midwifery,

Iran University of Medical Sciences, Tehran, Iran.

E-mail: shadikanani@rocketmail.com

DOI: $10.14260 /$ jemds/2018/986

\section{(c) (1) $(2)$}

abdominal neoplasms (Ferreira-Umpiérrez and Fort-Fort, 2014). The World Health Organization (WHO) defines the quality of life in five dimensions including physical health, mental health, independence, social and environmental issues (Taylor, 2012). People with stoma has various physical and mental health problems, which includes a negative image of themselves and a restriction on individual activities and lifestyle changes that include problems in their sexual life (Karabulut et al, 2014). Complications of stoma such as skin problems, leakage and adaptive problems can affect the patient's health quality of life (Dalmolin et al, 2016). Quality of life is a set of mental components which reflect the physical, emotional, occupational and social experiences of patients (Mahjoubi et al, 2012).1,2,3,4,5 Quality of life is an important dimension in patients with stoma. This group undergoes surgery, which can cause permanent changes to their quality of life. Most of these patients have colorectal cancer, so they have to deal with a wide range of surgical effects to adapt to the cancer. Due to the loss of some member parts and a major change which occur in anatomy and body function, these patients will experience various degrees of quality of life (Sarabi et al, 2011). That is, the function of a stoma leads to a sense of disability and exclusion from the family or society. Improving the quality of life is very necessary and vital, so the primary goal for caregivers and 
medical staff should be considered for this group of people (Golicki et al, 2013). Efforts to improve the quality of life of cancer patients as one of the most important results of treatment in oncology have led the treatment team to pay more attention to the various dimensions of quality of life in recent years and to search for effective ways to improve the quality of life of these patients. Meanwhile, the role of nurses is emphasised, since the role nurses play as a member of the treatment team is very vital in caring the patients with cancer and can identify the patient's and his family's care needs for controlling the complications of the disease and improve the quality of life is impressive (Dabirian et al, 2011). Nurses should play a vital role in caring stoma and helping patient's family help patients cope with new life (Dalmolin et al, 2016).6,7,8,9 The patient needs information about how to replace a stoma bag, care for the skin around the stoma, washing stoma, type and dietary intake, dietary restrictions and activity restrictions. So it should be said nursing care is a key part in bringing them back to normal life (Sarabi et al, 2011). Considering the fact that training to patients is currently a major issue in the related studies and the positive role of the family as an important collaborative resource in the pursuit of therapeutic goals is less (Zand et al, 2016a) family-centered education to some extent. The axis is a process in which family members learn to improve their skills and abilities to help a member of the family who is infected with the disease (Nayeri et al, 2011). Family-centered education is one of the main concepts of nursing and aims to maintain the patient's family integrity and provide unique care for each patient. In the family-centered education approach, the active participation of the family in the examination and diagnosis of needs is very important and in this regard there are trainings. Because it is believed that the occurrence of a disease in one person leads to the entry of single family member into the disease cycle (Sanaii et al, 2013). ${ }^{10,11}$ Family care is an important support in the process of chronic diseases, which positively affects the health and wellness system (Ferreira-Umpiérrez and Fort-Fort, 2014). This research investigates the impact of family-centered education on quality of life of the patients with stoma (colostomy and ileostomy).

\section{MATERIALS AND METHODS}

This research was a non-randomised clinical trial (semiexperimental) with the aim of investigating the effect of family-centered education on quality of life in people with stoma. The research environment was the colorectal clinics of Hazrat Rasoul-e-Akram Hospitals and Firoozgar Hospital. The criteria for entering the research include at least the reading and writing skills of the active member of the household and the client (due to the ability to research written materials), the active member of the family, the willingness and responsibility of the patient and the family member for collaboration, having a permanent or temporary stoma at least one month past from surgery, age (having at least 18 years of age and up to 60 years) (Salome et al, 2014); having mental health, speech, vision and hearing abilities and the delicate hand movements abilities were based on insertion in the case and according to the doctor's instructions (such as rheumatoid arthritis and upper limb).12,13,14,15 The exit criteria include patient's death, absent for meeting, complication incidence or severe disability during the research. During the research, a person with stomatitis and a family member of the test group refuse to continue the research. So, for the research 61 subjects ( 31 controls and 30 subjects) were selected. The research's main tool is to collect the required data. A verified standard questionnaire for the quality of life of patients with stoma (CHO-QOL) was designed by researchers at the National Heart Cancer Center of California. The second part of the research, the questionnaire consisted of 90 questions in three sections. The first section is the demographic information. The lifestyle stoma part has 34 questions with one-word responses in terms of occupation, health insurance status, sexual activity, psychological worries, dressing and diet, daily care of the stoma and food groups. This part response is not rated. Therefore, in this research, these questions were used to describe the samples. The third and basic part of the questionnaire assesses the effect of the stoma on quality of life which consists of 43 questions in terms of health dimensions, physical (Questions 1-11), psychological (Questions 12-24), social (25-36 questions) and spiritual (Questions 37-43) aspects of the quality of life. In this part, the questions will be scored from 0 to 10 according to the Likert rating scale and will be used to calculate the average quality of life score. In some questions, more points indicate a better quality of life and in some other questions lower score points out a better quality of life. To calculate the quality of life scores at first by applying reversal changes to negativegender questions, the mean score of quality of life in each its dimensions as well as in general were determined and for the quality of life of the whole and each of its dimensions the minimum score (best) and the maximum score of 10 (the weakest) were considered. Then they were judged by the average score obtained by the samples regarding the worse or better quality of life. The questionnaire validity and reliability in Iran was carried out by Naseh et al. In 2012, Cronbach's alpha coefficient 0.95 and correlation coefficient for physical, psychological, social and spiritual dimensions of quality of life were $0.82,0.88,0.83,78 / 0$ (Naseh et al, 2013).

After premising from the Iranian Nursing and Midwifery Faculty, the researcher approached the clinics of the abovementioned hospitals. ${ }^{16,17}$ He selected the samples according to the criteria for entering and obtaining informed consent and divided into two groups: Control, Family-Centered test (Active member of the family in the care field). The test group was divided into groups consisting 8 - 10 subjects. To prevent contamination, control group information from colorectal clinics of Hazrat Rasool Hospital and the test group were obtained from the referral. The colourful clinic of Firoozgar Hospital was selected.18,19 The questionnaire is presented personally by each. The groups completed and then the educational program was prepared as a manual on digestive stoma disease, delayed complications of osteoporosis, nutrition, exercise, travel, education and guidance on skin care around the stoma in 3 sessions of $30-45$ minutes in 3 weeks for the test group. Lecture sessions, group discussion and question and answer sessions were run using slides and educational booklets. A booklet which was containing explanations for gastric stoma, late appetite complications, nutrition, exercise, travel and guidance on skin care around stoma was available to individuals in the test groups. At the first session after introducing himself, the researcher introduced the subjects to each other, defined and explained 
the educational program, the purpose of the intervention and the importance of its work as well as information on the recognition of gastric stoma and its late complications. The second session of the previous session was reviewed and the way to replace the stoma bag is practical and the exercises were reviewed and the contents of the past sessions were reviewed in the third session and about skin care education around the stoma was said. At training sessions, training was provided as simple, understandable, as possible without applying the specialised medical terms. Upon completing the educational intervention until the post-test stage, the intervention group was requested to provide the principles trained when attending to operate at home. ${ }^{20,21,22,23}$

Again two months after the end of the intervention, two groups were asked to attend the clinic to complete the questionnaires. In the interval between the completion of the intervention and the post-test stage, to ensure the training program continuity, the researcher called the participants in the test groups three times in 5 to 10 minutes duration along with answering the questions, training process and evaluation care. Accordingly, during the intervention period, the control group received common education and training and the intervention group did not receive any training. In the intervention and control group in the pre-training and 2 months after training, the quality of life was measured through a standard quality of life questionnaire (OOI-CHOQOL) and finally the quality of life in the group was analysed. Then, data were analysed by SPSS Software 22 with Chisquare, t-test and independent t-test.

\section{RESULTS}

The mean age of subjects with gastric stoma in the experimental group was 48.8 with a standard deviation of 12.49 and in the control group was 54.48 years with a standard deviation of 8.99. The Body Mass Index (BMI) was $60 \%$ of the samples in the normal range. Of normal range 24 was $40 \%$ of the samples had a postgraduate degree. More than $50 \%$ of the samples had colon cancer and gastric stoma rectal. $53.3 \%$ of the cares were the patient's wife. According to Chi-square test, the quality of life data distribution was homogeneous and there was no significant statistical difference between the two groups in demographic variables (Table 1).

Before the intervention, the quality of life score in the control group and the experimental group were 6.71 and 6.67, respectively. There was no significant difference between the two groups before intervention $(p=0.883)$. After the intervention in the control group, the quality of life score was 6.28 and 5.84, respectively. Independent t-test showed that there was a significant difference between the two groups $(p=0.006)$. Except in the case of physical health between two groups, no statistically significant difference was observed (Table 2).

\begin{tabular}{|c|c|c|c|c|}
\hline \multicolumn{2}{|c|}{ Variable } & $\begin{array}{c}\text { Control } \\
\text { Group }\end{array}$ & $\begin{array}{c}\text { Family } \\
\text { Center }\end{array}$ & \multirow{2}{*}{ P } \\
\hline \multirow{2}{*}{ Gender } & Male & $18(58.1 \%)$ & $12(40 \%)$ & \multirow{2}{*}{0.345} \\
\cline { 2 - 4 } & Female & $13(41.9 \%)$ & $18(60 \%)$ & \\
\hline \multirow{3}{*}{ Marriage } & Single & $7(22.6 \%)$ & $2(6.7 \%)$ & \\
\cline { 2 - 4 } & Married & $23(74.2 \%)$ & $27(90 \%)$ & \multirow{2}{*}{0.576} \\
\cline { 2 - 4 } Income & Other Case & $1(3.2 \%)$ & $1(3.3)$ & \\
\cline { 2 - 4 } & Sufficient & $0(0 \%)$ & $0(0 \%)$ & \\
\cline { 2 - 5 } & Quite Enough & $21(67.7 \%)$ & $12(40 \%)$ & 0.094 \\
\hline
\end{tabular}

\begin{tabular}{|c|c|c|c|c|}
\hline & Not Enough & $10(32.3 \%)$ & $18(60 \%)$ & \\
\hline \multirow{4}{*}{ BMI } & Thin & $9(29 \%)$ & $7(23.3 \%)$ & \multirow{4}{*}{0.445} \\
\hline & Normal & $21(67.7 \%)$ & $18(60 \%)$ & \\
\hline & Overweight & $1(3.3 \%)$ & $4(13.3 \%)$ & \\
\hline & Obese & $0(0 \%)$ & $0(0 \%)$ & \\
\hline \multirow{4}{*}{$\begin{array}{c}\text { Reason } \\
\text { of Ostomy }\end{array}$} & $\begin{array}{l}\text { Colon Cancer } \\
\text { and Rectum }\end{array}$ & 26 (83.9\%) & $23(76.7 \%)$ & \multirow{4}{*}{0.306} \\
\hline & Other Cancers & $4(12.9 \%)$ & $1(3.3 \%)$ & \\
\hline & $\begin{array}{c}\text { Inflammatory } \\
\text { Diseases }\end{array}$ & $0(0 \%)$ & $3(10 \%)$ & \\
\hline & Other Cases & $1(3.2 \%)$ & $3(10 \%)$ & \\
\hline \multirow{4}{*}{$\begin{array}{l}\text { Ostomy } \\
\text { Kind }\end{array}$} & $\begin{array}{l}\text { Permanent } \\
\text { Ileostomy }\end{array}$ & $1(3.2 \%)$ & $4(13.3 \%)$ & \multirow{4}{*}{0.245} \\
\hline & $\begin{array}{l}\text { Temporary } \\
\text { Ileostomy }\end{array}$ & $1(3.2 \%)$ & $0(0 \%)$ & \\
\hline & $\begin{array}{l}\text { Permanent } \\
\text { colostomy }\end{array}$ & $22(71 \%)$ & $24(80 \%)$ & \\
\hline & $\begin{array}{l}\text { Temporary } \\
\text { colostomy }\end{array}$ & 7 (22.6\%) & $2(6.7 \%)$ & \\
\hline
\end{tabular}

Table 1. Compares the Demographic Characteristics of the Participants at Baseline

\begin{tabular}{|c|c|c|c|c|}
\hline & Groups & Control & \begin{tabular}{|c|} 
Interventio \\
n Group $^{2}$ \\
(Family \\
Centered) \\
\end{tabular} & $\mathbf{P}$ \\
\hline & \begin{tabular}{|l|} 
COH-QOL \\
\end{tabular} & Mean \pm SD & Mean \pm SD & \\
\hline \multirow{5}{*}{ 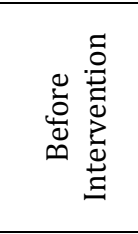 } & Physical health & $7.06 \pm 0.96$ & $6.83 \pm 1.50$ & 0.483 \\
\hline & \begin{tabular}{|l|} 
Mental health \\
\end{tabular} & $6.52 \pm 0.74$ & $6.57 \pm 0.59$ & 0.804 \\
\hline & Social health & $7.78 \pm 0.72$ & & 0.615 \\
\hline & $\begin{array}{c}\text { Spiritual } \\
\text { health }\end{array}$ & $5.46 \pm 0.86$ & $5.41 \pm 0.86$ & 0.834 \\
\hline & \begin{tabular}{|l|} 
Quality of life \\
\end{tabular} & $6.71 \pm 0.53$ & $6.67 \pm 0.72$ & 0.843 \\
\hline \multirow{5}{*}{ 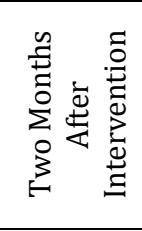 } & Physical health & $6.56 \pm 0.72$ & $5.47 \pm 0.86$ & 0.000 \\
\hline & Mental health & $5.78 \pm 0.45$ & $5.67 \pm 0.68$ & 0.463 \\
\hline & Social health & $7.56 \pm 1.45$ & $7.23 \pm 1.21$ & 0.357 \\
\hline & $\begin{array}{c}\text { Spiritual } \\
\text { health }\end{array}$ & $5.20 \pm 0.74$ & $4.99 \pm 0.81$ & 0.305 \\
\hline & Quality of life & $6.28 \pm 0.61$ & $5.84 \pm 0.57$ & 0.006 \\
\hline
\end{tabular}

\section{DISCUSSION}

The research's aim was to investigate the impact of familycentered education on quality of life in people with stoma. The results showed in the family-centered group before the intervention, the quality of life mean score was $6.67 \pm$ 72.9.24,25 Two months after the intervention, the quality of life mean score was $5.84 \pm 5.70$. Statistical analysis showed before intervention and two months after that, quality of life mean score was significantly different in family-group $(p=0.006)$. In confirming these results, Srisuk et al (2014) in research on the family-centered educational programs for patients with chronic heart failure in rural Thailand showed after conducting training sessions for 50 patients and their family members, their caregivers were increased. In the intervention group, family members' knowledge and self-care of the patients were compared to the control group who received general care training. Similarly, Dunbar et al (2013) in the research. As a trial to compare family partnerships and educational interventions on heart failure, they showed the self-care providers rate include receiving less sodium in the diet in the patient education group and the family had a significant increase compared to the control group four months after training $(\mathrm{p}=0.04)$ and eight months after 
training $(\mathrm{p}=0.02)$. As such, a research by Stamp et al (2015) showed family-centered training and interventions had a significant effect on self-care in patients with chronic heart failure in some cases including $\operatorname{diet}(\mathrm{p}=0.02)$ and compliance with drug orders $(\mathrm{p}=0.05)$. Another research by Ghavidel et al (2015) entitled "Family-centered education" focuses on quality of life after postoperative surgery. Coronary Artery Bypass showed at the next stage of the test, the quality of life dimensions of the test group were significantly increased compared to the control group $(\mathrm{p}<0.001)$. Family-centered education for patients undergoing coronary artery bypass graft surgery could improve the patients' quality of life. Also, Babazade et al (2017) in a research entitled "The effect of educational intervention based on family-centered empowerment model in modifying high-risk behaviours in patients with brucellosis showed that the mean of all constructs (attitude, self-efficacy, dignity, self-esteem and behaviour) were significantly increased in the intervention group compared with the control group $(\mathrm{p}<0.001)$. Rabiei et al (2012) in a research titled "The Effect of Family-Based Empowerment Pattern on Knowledge, Attitude and Practice of Multiple Sclerosis patients," the Mann-Whitney test showed before the two groups sometimes they were similar, but after intervention there was a significant difference between the two groups' knowledge ( $p<0.001)$. Zand et al (2016b) research titled "The effect of education" (familycentered and patient-centered) through multimedia software on heart rate abnormalities in patients with acute myocardial infarction, there was no significant difference between the two groups. But three months after the intervention, the two groups showed a significant difference in heart rate abnormalities. According to the results, family-centered education is more effective in reducing heart rate abnormalities than patient-centered education. Also, Asgari et al (2017) in their research titled the effect of familycentered education on the laboratory parameters of patients after acute myocardial infarction showed the therapeutic outcomes include blood glucose levels $(p=0.03)$ and blood lipids (TG, LDL). LDH, Chol $(p=0.001)$ in the family-based group had a significant difference with the patient-centered group. However, there was no significant difference between the two groups before the intervention in the mentioned cases. This research was consistent with the present research and the research mentioned in this research showed the effect of family-centered education on patients' quality of life positively and significantly.

Findings: The present research showed that improving the quality of life in the test group under the influence of family-centered education sessions, raising the level of knowledge and family ability for quality care of gastroenterologists, familiarising them with complications and providing appropriate strategies and consistent and continuous communication with the next test group from hospital clearance.

In a research by Aggarwal et al (2010) titled "Low social support" and its association with non-compliance with diet during one year in family-centered interventional interventions for heart health showed having appropriate social support for the patient. One of the most important factors for adherence to the diet after hospital discharge is considered. In patients who did not have proper family support, the dietary intake was significantly reduced after discharge. Opara et al (2010), who conducted a supportive intervention for the family of patients with stroke in the test group of patients. The life quality of the patient and his family increased and the feeling of pressure on patient care was reduced considerably. The results showed simple and understandable training in a few sessions for the family of gastroenterologists in post-clearance care with the follow-up of educational programs has led to a significant improvement in the life quality and consequently the quality of care for these people were increased.

The results of this research are not consistent with Davodi et al (2012), who studied the effect of self-care education on the life of quality gastric cancer patients in gastrostomy surgery. The results showed general life quality based on the quality of life questionnaire for cancer patients before and after the intervention was not significant in the control and experimental groups, but in emotional functioning the experimental group had a significant difference in the dimensions of global quality of life and physical problems. The difference in quality of life mean score between two groups before and after the intervention was not significant based on two questionnaires. ${ }^{26}$

But there was a difference in emotional and psychological functioning. Perhaps some of the reasons for the inconsistency of the results are as follows: the difference in the type of educational intervention in two studies and the statistical population of the research referred to include gastric cancer patients after stoma surgery, while the statistical population in this research was patients with gastric stomatitis. Another important point to keep in mind is the age, personal characteristics and cultural differences of patients and their perceptions of the various components of quality of life which affect their quality of life mean score, so this can be one of the reasons for not matching the two researches.

\section{CONCLUSION}

Family-centered education approach implementation showed a significant difference in the quality of life score of patients with stoma associated with improving the quality of life of these patients.

\section{ACKNOWLEDGEMENT}

This study is extracted from a research project approved by Vice President of Research of Iran University of Medical Science with code: IR.IUMS.REC.1396.9511686006 and is registered in Iranian registry of clinical trials center with code IRCT: IRCT20180628040265N1.

\section{REFERENCES}

[1] Aggarwal B, Liao M, Allegrante JP, et al. Low social support level is associated with non-adherence to diet at 1 year in the Family Intervention Trial for Heart Health (FIT Heart). Journal of Nutrition Education and Behavior 2010;42(6):380-8.

[2] Asgari P, Bahramnezhad F, Golitaleb M. et al. The effect of family-centered education on the laboratory index of patients after acute myocardial infarction. Journal of Sabzevar University of Medical Sciences 2017;24(1):43-9.

[3] Babazade T, Banaijedi M, Shojaiezade F, et al. The impact of family-based empowerment intervention on improving high-risk behavior in patients with 
brucellosis. Hakim Magazine Seyed Esmaeel Jorjani 2017;4(2):10-4.

[4] Dabirian A, Yaghmaee F, Rasouli M. Ostomy patient's quality of life: a qualitative study. Ind J of Nursing Research 2011;6(20):75-82.

[5] Dalmolin A, Girardon-Perlini NMO, Coppetti LC, et al. Educational video as a healthcare education resource for people with colostomy and their families. Revista Gaúcha de Enfermagem 2016;37(Spe):e68373.

[6] Davodi A, Rezazade H, Hosiensomi M, et al. The effect of self-care program training on the quality of life of gastric cancer patients from gastrectomy surgery. Medical Journal of Tabriz University of Medical Sciences 2012;34(1):48-55.

[7] Dunbar SB, Clark PC, Reilly CM, et al. A trial of family partnership and education intervention in heart failure. Journal of Cardiac Failure 2013;19(12):829-41.

[8] Ferreira-Umpiérrez A, Fort-Fort Z. Experiences of family members of patients with colostomies and expectations about professional intervention. Revista Latino-Americana de Enfermagem 2014;22(2):241-7.

[9] Fucini C, Gattai R, Urena C, et al. Quality of life among five - year survivors after treatment for very low rectal cancer with or without a permanent abdominal stoma. Annals of Surgical Oncology 2008;15(4):1099-106.

[10] Ghavidel, Alireza, Farokhnezhad-Afshar, et al. Effect of family-centered education on the quality of life patients after coronary artery bypass graft surgery. Cardiovascular Nursing Journal 2015;4(2):6-13.

[11] Golicki M, Styczen P, Szczepkowwski M. Quality of life in patients with Ostomy in Poland: multicentre crosssectional study using WHOQOL-BREF questionnaier. Value in Health: The Journal of International Society for Pharmacoeconomics \& Outcomes Research 2013;16(7):A421.

[12] Hoentjen F, Colwell JC, Hanauer SB. Complications of peristomal recurrence of Crohn's disease: a case report and a review of literature. Journal of Wound Ostomy \& Continence Nursing 2012;39(3):297-301.

[13] Karabulut HK, Dinc L, Karadag A. Effects of planned group interactions on the social adaptation of individuals with an intestinal stoma: a quantitative study. Journal of Clinical Nursing 2014;23(1920):2800-13.

[14] Mahjoubi B, Mirzaei R, Azizi R, et al. A cross-sectional survey of quality of life in colostomates: a report from Iran. Health and Quality of Life Outcomes 2012;10:136.

[15] Naseh L, Rafi F, Moghadesi J, et al. Quality of life and its dimensions in patients with ostomy. Clinical Journal of Nursing and Midwifery 2013;1(1):10-22.
[16] Sanaie N, Nejati S, Zolfaghari M, et al. The effect of family-centered empowerment on self-efficacy and self-esteem of patients undergoing coronary bypass graft surgery. Journal of Research Development in Nursing and Midwifery 2013;10(2):44-53.

[17] Sarabi N, Nasiri-Ziba F, Safarabadi - Farahani T. et al. A survey of ostomy patient satisfaction with nursing care. Iran Journal of Nursing 2011;24(69):43-52.

[18] Srisuk N, Cameron J, Ski CF, et al. Trial of a familybased education program for heart failure patient in rural Thailand. BMC Cardiovascular Disorders 2014;14:173.

[19] Stamp KD, Dunbar SB, Clark PC, et al. Family partner intervention influences self-care confidence and treatment self-regulation in patients with heart failure. European Journal of Cardiovascular Nursing 2015;1:14-20.

[20] Nayeri ND, Mohammadi S, Arazi T. Examining the level of adherence of therapeutic regime by the family caregivers of stroke patients. Canadian Journal of Medicine 2011.

[21] Oupra R, Griffiths R, Pryor J, et al. Effectiveness of supportive educative Learning programme on the level of strain experienced by caregivers of stroke patients in Thailand. Health \& Social Care Community 2010;18(1):10-20.

[22] Rabiei L, Sharifirad G, Masoodi R, et al. Knowledge, attitude and skill of multiple sclerosis patients; the effect of family - centered empowerment model. Health Research Journal 2012;8(2):247-59.

[23] Salome GM, De Almeida SA, Silveira MM. Quality of life and self-esteem of patients with intestinal stoma. Journal of Coloproctology (Rio de Janeiro) 2014;34(4):231-9.

[24] Taylor C. Reach for recovery: evaluating a pilot study of a colorectal cancer survivorship programme. European Journal of Oncology Nursing 2012;30(1):7.

[25] Zand S, Asgari P, Bahramnezhad F, et al. The effect of two educational methods (family - centered and patient-centered) multimedia software on dysrhythmia of patients after acute myocardial infarction. Journal of Health 2016a;7(1):7-17.

[26] Zand S, Asgari P, Bahramnezhad F, et al. The effect of two educational methods (family - centered and patient-centered) multimedia software on dysrhythmia of patients after acute myocardial infarction. Journal of Health 2016b;7(1):7-17. 